\title{
The virulence factor ychO has a pleiotropic action in an Avian Pathogenic Escherichia coli (APEC) strain
}

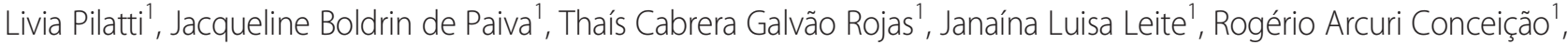 \\ Gerson Nakazato ${ }^{2}$ and Wanderley Dias da Silveira ${ }^{1 *}$
}

\begin{abstract}
Background: Avian pathogenic Escherichia coli strains cause extraintestinal diseases in birds, leading to substantial economic losses to the poultry industry worldwide. Bacteria that invade cells can overcome the host humoral immune response, resulting in a higher pathogenicity potential. Invasins are members of a large family of outer membrane proteins that allow pathogen invasion into host cells by interacting with specific receptors on the cell surface.
\end{abstract}

Results: An in silico analysis of the genome of a septicemic APEC strain (SEPT362) demonstrated the presence of a putative invasin homologous to the $y c h O$ gene from E. coli str. K-12 substr. MG1655. In vitro and in vivo assays comparing a mutant strain carrying a null mutation of this gene, a complemented strain, and its counterpart wildtype strain showed that $y c h O$ plays a role in the pathogenicity of APEC strain SEPT362. In vitro assays demonstrated that the mutant strain exhibited significant decreases in bacterial adhesiveness and invasiveness in chicken cells and biofilm formation. In vivo assay indicated a decrease in pathogenicity of the mutant strain. Moreover, transcriptome analysis demonstrated that the $y c h O$ deletion affected the expression of 426 genes. Among the altered genes, $93.66 \%$ were downregulated in the mutant, including membrane proteins and metabolism genes.

Conclusion: The results led us to propose that gene ychO contributes to the pathogenicity of APEC strain SEPT362 influencing, in a pleiotropic manner, many biological characteristics, such as adhesion and invasion of in vitro cultured cells, biofilm formation and motility, which could be due to the possible membrane location of this protein. All of these results suggest that the absence of gene $y c h O$ would influence the virulence of the APEC strain herein studied.

Keywords: Escherichia coli, APEC, ychO, Virulence, Pathogenicity

\section{Background}

Escherichia coli strains that cause diseases outside the intestine are known as extraintestinal pathogenic E. coli (ExPEC). These strains include human uropathogenic $E$. coli (UPEC), neonatal meningitis E. coli (NMEC) and avian pathogenic E. coli (APEC) [1-3]. APEC are frequently associated with extraintestinal infections in poultry, leading to respiratory or systemic diseases, which are responsible for large economic losses to the

\footnotetext{
* Correspondence: wds@unicamp.br

'Department of Genetics, Evolution and Bioagents, Institute of Biology (P.O.Box: 6109), State University of Campinas - UNICAMP (ZIP Code 13083970), Campinas, São Paulo, Brazil

Full list of author information is available at the end of the article
}

poultry industry worldwide $[4,5]$. Colibacillosis is a general term used to describe the large number of existing infections, including septicemia, cellulitis, omphalitis, peritonitis, respiratory tract infections, the egg yolk disease and swollen head syndrome. Colisepticemia, the most severe systemic disease, is characterized by pericarditis, perihepatitis and airsacculitis, and it leads to multiple organ failure and death $[6,7]$. In APEC, although several virulence factors such as adhesins, secretion and iron uptake systems, increased serum survival and cytotoxic proteins, have already been identified $[1,6,8]$, many others could exist and participate in the pathogenicity process. These currently unknown virulence factors 
could play major roles in pathogenicity and could be significant for the development of measures for controlling the infectious processes.

Adherence to and invasion of host cells are important steps in the pathogenesis of many bacteria [9]. Bacterial adherence is mediated by adhesins, which recognize receptors on the cell surface. Bacteria that invade host cells possess an important advantage in pathogenicity, overcoming the humoral immune response [10]. A large family of bacterial outer membrane proteins facilitates the entry of the pathogen into host cells by allowing tight adherence to and invasion of the cells. This family of proteins interacts with receptors displayed on the cell surface, triggering signaling cascades to rearrange the host cell cytoskeleton and induce the uptake of bacteria $[11,12]$. The first two members of this family (intimin and invasin), although acting differently to promote the invasion of host cells, show significant sequence similarity, especially in the amino terminal region $[13,14]$. The first invasin (inv) to be described is produced by Yersinia pseudotuberculosis and $Y$. enterocolitica [14], and it mediates bacterial entry into eukaryotic cells by high-affinity binding to members of the $\beta_{1}$ integrin family $[12,15]$, which are heterodimeric integral membrane proteins that mediate communication between the extracellular environment and the cytoskeleton [16]. The intimins, implicated in attaching and effacing lesions, are produced by enterohemorrhagic (EHEC) and enteropathogenic E. coli (EPEC) [13, 17]. In contrast to invasin, the receptor for intimin binding is Tir (Translocated Intimin Receptor), a protein that is secreted into the host cell membrane by the bacterium itself [18]. The intimins and invasins have similar domain structures: an $\mathrm{N}$-terminal signal sequence, a conserved $\beta$-barrel domain, and a $\mathrm{C}$-terminal passenger domain (the transported part of the protein) [19]. The $\beta$-barrel structure is necessary for the passenger domain, which mediates interactions with host cells, to cross the outer membrane [20].

The in silico analysis of recently sequenced genomes of some APEC strains [21-23] enabled the identification of possible new virulence genes that could lead to a better understanding of the infectious process. The in silico analysis of the sequenced genome of the APEC strain SEPT362 [22, 24] identified a putative invasin gene, which is homologous to the not yet described $y$ chO gene from E. coli str. K-12 substr. MG1655 (98 \% of identity) and is present in 120 sequenced $E$. coli strains (NCBI). The role of this protein in pathogenicity or biological function of the APEC strains was not previously established, and considering the importance of intimin/invasin-like proteins in other Gram-negative pathogens, this work aimed to test the hypothesis that $y$ chO might contribute to the pathogenesis of APEC strain SEPT362. In this work we showed that the $y c h \mathrm{O}$ gene is highly expressed in the lungs and spleen during in vivo infection assays by strain SEPT362, what suggests the importance of this gene in in vivo colonization of the host. A mutant strain for gene $y c h \mathrm{O}$ was constructed for in vivo and in vitro comparative analysis with the complemented strain and its counterpart wild-type strain. In this study, we demonstrated, for the first time, that the gene $y c h \mathrm{O}$ is expressed in vitro and in vivo and is involved in the bacterial capacity for adhesion to and invasion of cultivated cells in vitro, motility and biofilm formation and also influences the pathogenicity and the expression of many other genes. These properties are important for pathogenicity in vivo, and our results suggest an important role for $y c h \mathrm{O}$ in the pathogenesis of strain SEPT362.

\section{Results and discussion}

\section{In silico characterization of the putative invasin gene ycho}

The APEC strain SEPT362 was isolated from the liver of a laying hen presenting clinical signs of septicemia [24]. A survey of the genome of strain SEPT362 [GenBank: AOGL00000000.1] revealed a putative invasin homologous to the $y c h \mathrm{O}$ gene from $E$. coli str. K-12 substr. MG1655 (98 \% identity). To initiate this work, the reannotation of this gene using RAST [25] was first performed, which showed a signal peptide sequence of $141 \mathrm{bp}$ that was not present in the GI:449323183 protein annotated in the SEPT362 genome. This peptide was considered to be part of the gene because it is known that this $\mathrm{N}$-terminal signal sequence is an important domain of a typical invasin, predicted to mediate the translocation of the protein from the bacterial cytoplasm through the inner membrane [26]. The $y c h \mathrm{O}$ product alignment also showed that different $E$. coli pathotypes possess a peptide signal on this protein, reinforcing the decision to retain this sequence as part of the gene for the mutant construction. This protein contains an $\mathrm{N}$ terminal signal sequence, a conserved $\beta$-domain that forms a transmembrane $\beta$-barrel structure, and a $\mathrm{C}$ terminal passenger domain that could be exported to the outside of the cell. These domains together are the main characteristics of the intimin/invasin superfamily. The intimin/invasin-like proteins normally form a longer structure, after the passenger domain, composed of repeated bacterial immunoglobulin-like domains (BID). In some cases, C-type lectin-like domains are present at the C-terminus [27]. These structures were not found in the YchO protein.

\section{ychO expression in vitro and in vivo}

In this study, first, $y c h \mathrm{O}$ expression was verified in the APEC strain SEPT362 (Fig. 1). The results showed that this gene is expressed not only in culture conditions but is highly expressed in the lungs and spleen of chicks 24 and 


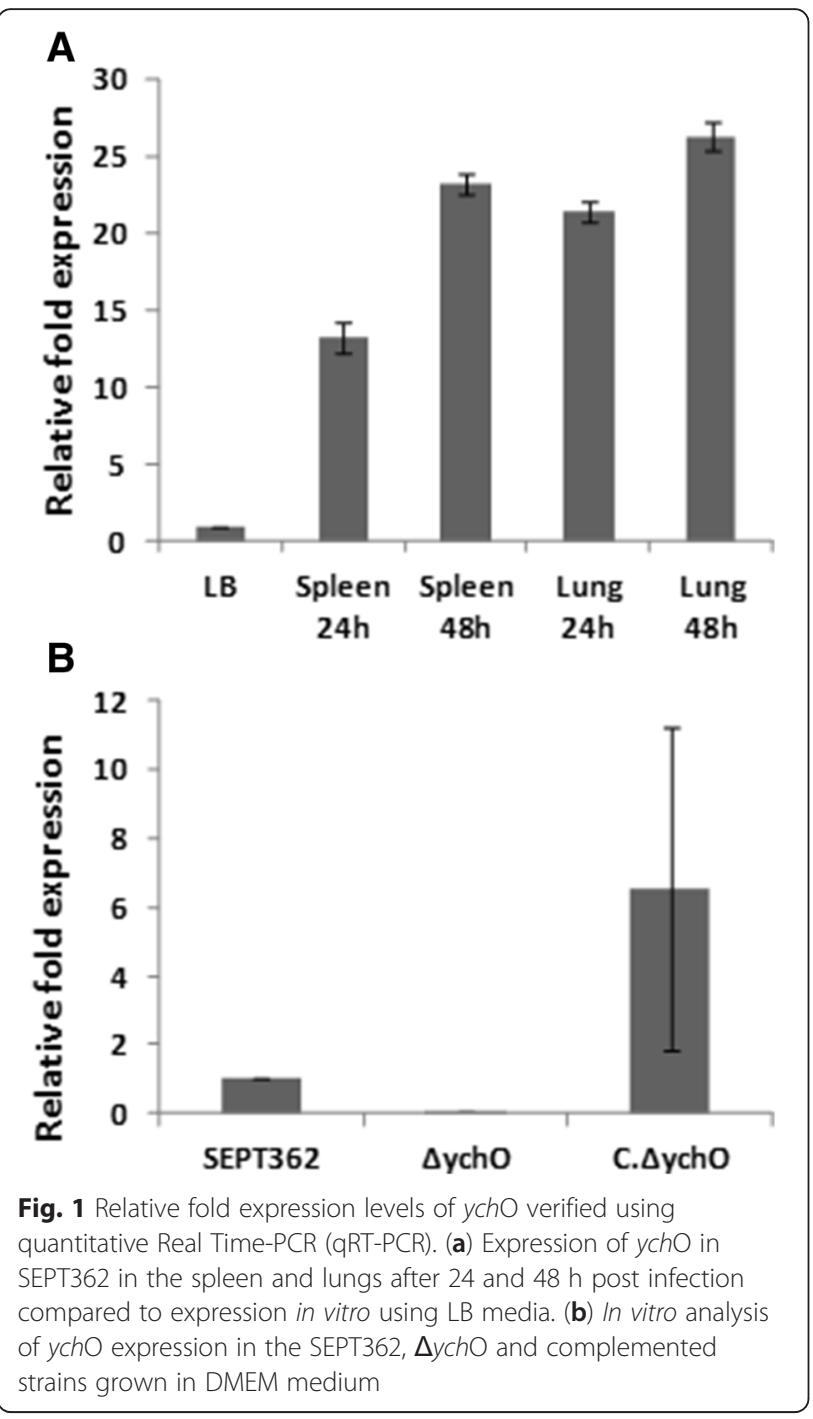

$48 \mathrm{~h}$ after inoculation, which suggests the importance of this gene in in vivo colonization of the host. With these results, a mutant strain of the $y c h \mathrm{O}$ gene and a complemented derivative strain containing the wild-type gene on a plasmid were constructed for comparative analysis with the wild-type APEC strain SEPT362. The mutant and complemented strains were verified by quantitative Real TimePCR (qRT-PCR). The high expression and high standard deviation of $y c h \mathrm{O}$ expression in complemented strain is related to the number of plasmid copies present in this strain, which has an average of 15 copies per cell [28]. A growth curve was constructed for the three strains, using LB and DMEM media. No differences were found between strains in both growing conditions (data not shown).

\section{The influence of the $y c h 0$ gene on SEPT362 cell adherence}

Invasins are a class of proteins that allow bacteria to penetrate cells, normally by tight adherence to and invasion of eukaryotic cells [11, 12]. Adherence and invasion are important steps for bacterial pathogenesis and contribute to the colonization, persistence and dissemination of a pathogen in the host organism $[9,10$, $29,30]$. Therefore, understanding the role of a possible invasin might help to elucidate the mechanisms of invasion and pathogenicity of host cells.

The capacity of the strains to adhere to chicken embryonic fibroblasts cell line CEF was assessed to understand the possible influence of $y c h \mathrm{O}$ gene on this phenotype. Because type 1 fimbriae binds to D-mannose residues and is important for APEC adherence to chicken cells [31-33], adhesion assays were also performed in the presence of alpha-D-mannopyranoside (D-mannose analog), a potent non metabolized FimH antagonist. The number of bacteria that adhered to prefixed CEF cells was significantly lower for the $y$ chO mutant than for the wild-type strain in the presence and absence of methyl-alpha-D-mannopyranoside (Fig. 2a). The decrease in the presence of a D-mannose analog shows that the disorder was not due to a disturb in type 1 fimbriae expression. The complemented strain restored the bacterial adhesion. These data suggest that $y c h \mathrm{O}$ is involved in SEPT362 adherence. To investigate whether the change in adhesion ability was due to a disturbance in the expression of other genes possibly related to the adhesion capacity of this strain, different bacterial adhesin genes (adhesin fim $\mathrm{H}[34,35]$, E. coli common pilus ecp [36], long polar fimbria subunit A lpfA [37], curlin fimbriae csgA [38], autotransporters aat $\mathrm{A}[39,40]$ and aat $\mathrm{B}[41])$, that were identified by in silico analysis to exist in the genome of strain SEPT362, were studied by qRT-PCR (Fig. 2b). The expression levels of these genes were not significantly changed indicating that none of these genes are influenced by the lack of $y c h \mathrm{O}$, and the decreased adherence of the mutant strain is not due to a decreased expression of those genes. Thus, even without the BIDs and the C-type lectin-like domains [42, 43], the YchO probably acts as an adhesin in APEC strain SEPT362.

\section{Gene ycho contributes to the invasion of chicken embryonic fibroblast cells}

We assessed the ability of SEPT362 to invade the chicken embryonic fibroblast cell line CEC-32 and the potential contribution of the $y c h \mathrm{O}$ gene to this phenotype. This cell line of avian origin was chosen because it resembles the environment bacteria would find in vivo. SEPT362 was able to invade CEC-32 cells efficiently, and the $y c h \mathrm{O}$ gene played an important role in this phenotype. The invasion assay was performed with two sets of cells: one set was lysed immediately after incubation with $50 \mu \mathrm{g} \mathrm{ml}^{-1}$ of gentamycin and the other was lysed after $1.5 \mathrm{~h}$ of incubation with 


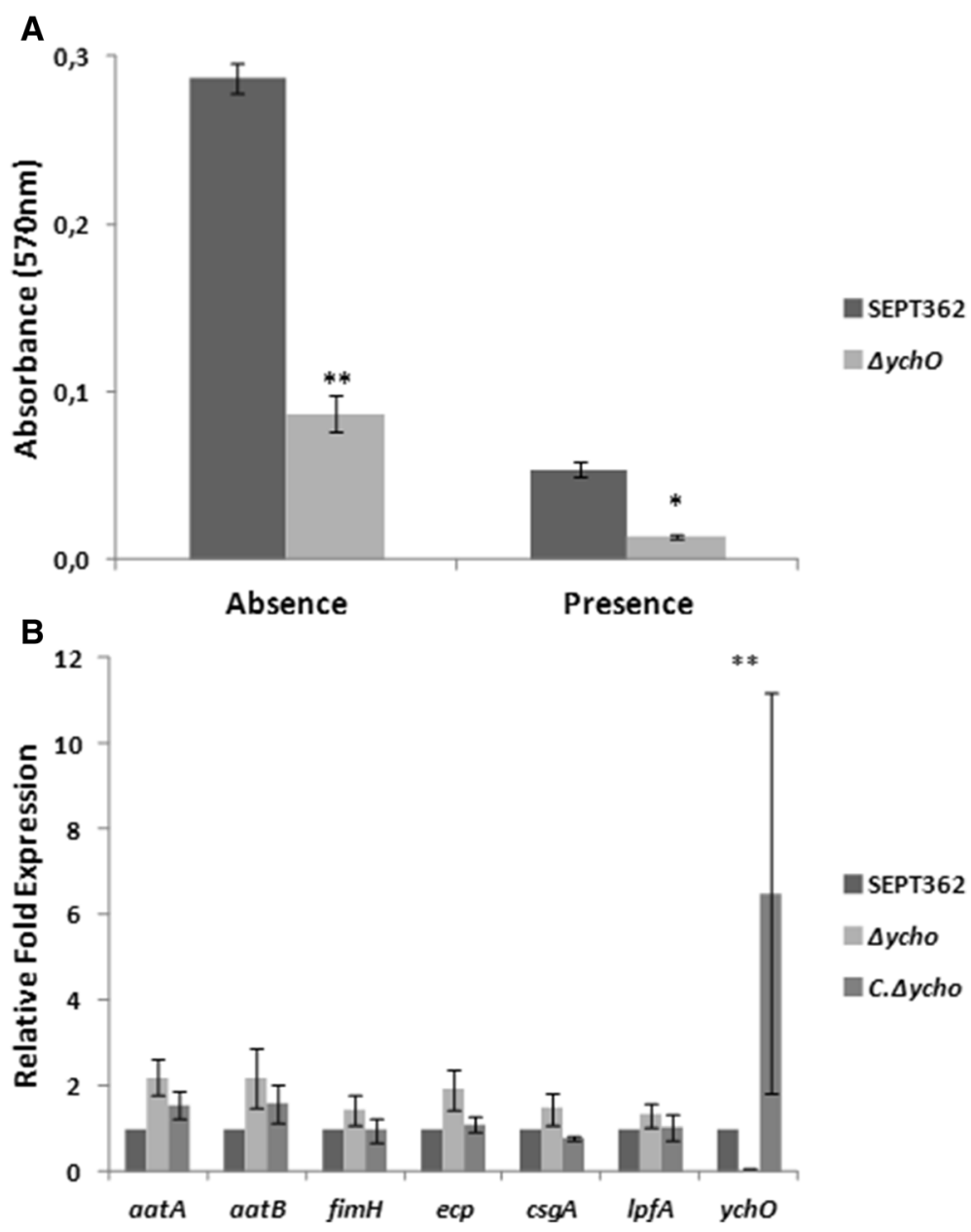

Fig. 2 Bacterial adhesion assay. (a) Comparison of adhesion between the strains. Quantification of bacteria adhered to the chicken embryo fibroblast cell line (CEF) in the absence or presence of methyl-alpha-D-mannopyranoside. (b) Relative fold expression of genes related to adhesion in SEPT362 verified using quantitative Real Time-PCR (qRT-PCR). Statistical significance was determined by Tukey's test in comparison with SEPT362 (**, $p<0.01 ; *, p<0.05)$

$5 \mu \mathrm{g} \mathrm{ml}{ }^{-1}$ of gentamicyn. The number of viable bacteria inside cells after the invasion assay was significantly lower in strain $\Delta y c h \mathrm{O}$ than in the wild-type strain, whereas the complemented strain restored this capacity (Fig. 3). The decreased invasiveness was significant, but was not completely abolished. This results suggest that other genes reported to be related to invasion, such as fliC (flagellin), motA (flagellar motor protein), bamB (outer membrane protein biogenesis), ompA (outer membrane protein A), ibeB (invasion protein), among others [44-46] that are present in this strain could also contribute to this process. After 1.5 hour of invasion, the number of surviving viable mutants was decreased while the wild-type and complemented strains retained their viability. These data suggest that this protein plays a role not only in invasion, but also in bacterial survival in this cell type.

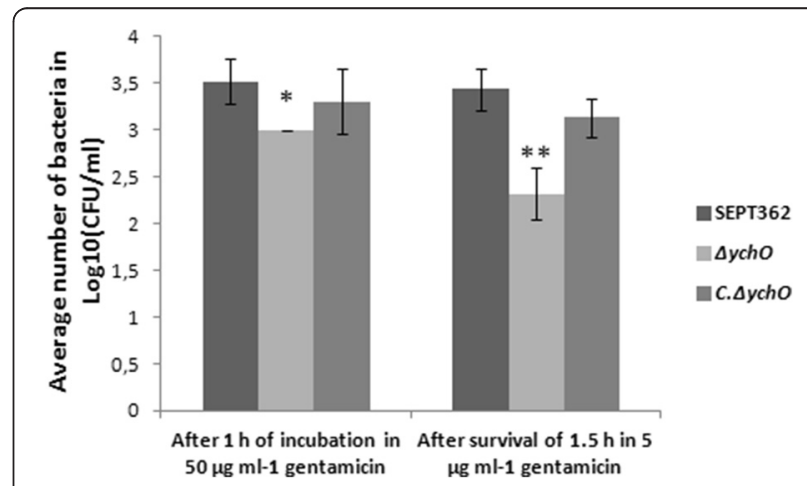

Fig. 3 Invasion assay in CEC-32. Comparison of strains after $1 \mathrm{~h}$ of incubation in $50 \mathrm{\mu g} \mathrm{ml}^{-1}$ gentamicin and survival after $1.5 \mathrm{~h}$ in $5 \mathrm{\mu g} \mathrm{ml}^{-1}$ gentamicin. Statistical significance was determined by Tukey's test in comparison with the count of the strain SEPT362 $\left(* *, p<0.01,{ }^{*}, p<0.05\right)$ 


\section{Biofilm formation is influenced by ych0}

Biofilms are multicellular communities within a selfproduced extracellular matrix attached to a surface [47, 48]. The extracellular matrix helps resist environmental changes and avoid host defenses. Given the capacity of strain SEPT362 to form biofilms on abiotic surfaces [49], we assessed this ability in the mutant strain using the crystal violet biofilm test on polystyrene (Fig. 4). Although the growth curves of strains $\Delta y c h \mathrm{O}$ and the C. $\Delta y c h \mathrm{O}$ did not show any difference when compared with the wild-type strain (data not shown), strain $\Delta y c h \mathrm{O}$ formed $50 \%$ less biofilm than the wild-type strain after $24 \mathrm{~h}$, indicating that $y c h \mathrm{O}$ influences biofilm formation. The complemented strain formed $35 \%$ more biofilm than the wild-type strain, which is explained by the overexpression of the gene in its plasmidial structure and suggests the importance of this protein in biofilm formation. These results corroborate a previous report in which a similar putative invasin protein of Edwardsiella tarda was found to be essential for biofilm formation [50], even though this protein contains a long structure of repeated BID, whereas $y c h \mathrm{O}$ does not.

\section{The lack of $y c h O$ affects the virulence of strain SEPT362}

In vivo assays were used to evaluate the pathogenicity of strain SEPT362 and its derivatives. For this purpose, separated groups of one-day-old chicks $(n=20$ on each group) were infected with the mutant, its complemented derivative and the wild-type strain (Fig. 5). The percent survival of chicks infected with the wild-type was $70 \%$ on the first day, $30 \%$ on the third day, and $10 \%$ at the end of the experiment. For strain $\Delta y c h \mathrm{O}$, the percent survival was $65 \%$ on the first day, $60 \%$ on the third day, and $40 \%$ at the end of the seventh day. No mortality was observed for the negative control infected with $10^{9} \mathrm{CFU} \mathrm{m} \mathrm{m}^{-1}$ of E. coli DH1Oß (data not shown). Although there were no significant differences among the strains considering the seven days of the experiment

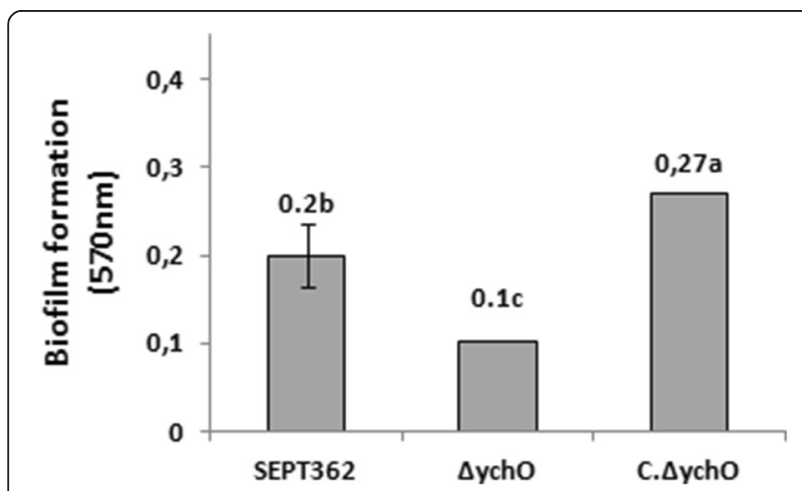

Fig. 4 Biofilm formation. Cells were grown for $24 \mathrm{~h}$ in polystyrene plates with DMEM. Averages followed by different letters are significantly different (Tukey, $\mathrm{p}<0.05$ )

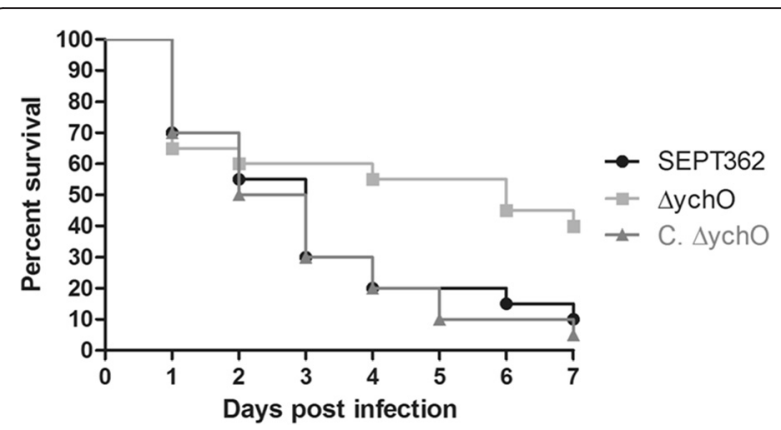

Fig. 5 Survival assay. One-day-old broiler chicks were infected with $10^{9} \mathrm{CFU} \mathrm{ml}{ }^{-1}$ bacteria $(n=20)$. There was no statistical significance determined by the Log-rank (Mantel-Cox) test compared with the SEPT362 strain $(p>0.05)$

(Log-rank test, $\mathrm{p}>0.05$ ), a significant change in the survival profile of the mutant strain compared to the wildtype was observed, after the second day (Log-rank test, $\mathrm{p}>0.05$ ). The complemented strain presented a profile similar to that of the wild-type strain. The lack of $y c h \mathrm{O}$ gene decreases the virulence of strain SEPT362 after $48 \mathrm{~h}$ in the host, which indicates YchO has a role in survival of the strain in the host. Although this gene is also found in non pathogenic E. coli strains, all of these results suggest that the absence of gene $y c h \mathrm{O}$ influences the virulence of the APEC strain herein studied in a direct way.

It is known that APEC pathogenesis is controlled by a number of virulence factors, including adhesins (F1-, P-, $\mathrm{AC} / \mathrm{I}-$, and F17-fimbriae, curli fimbriae, and afimbrial adhesins), iron acquisition systems (aerobactin and yersiniabactin), hemolysins and the temperature-sensitive hemagglutinin Tsh, antibactericidal factors (outer membrane protein A, a protein for increased serum survival, lipopolysaccharide, K1-capsule, and colicin production), and toxins (heat stable toxin, cyto-/verotoxin, flagella toxin, and vacuolating autotransporter toxin) [4, 51-59]. Many of these virulence factors $(f i m \mathrm{H}, t s h \mathrm{H}, f l i \mathrm{C}, i c m \mathrm{~F}$, iuc $\mathrm{C}$, yoe $\mathrm{B}$, among others) have been found in strain SEPT362 by in silico search and in vivo analysis [22, 24, 49], which most likely makes the pathogenicity of this strain multifactorial. Thus, $y$ chO activity is one of several factors that could contribute to SEPT362 pathogenicity, and the full virulence observed in this strain would result from the sum of all the virulence factors present in it.

\section{The lack of ychO affected the expression several genes in SEPT362 strain}

The results presented so far showed that $y c h \mathrm{O}$ gene has a pleiotropic effect on several biological characteristics, including those related to invasin like proteins, such as biofilm formation, adhesion to and invasion of in vitro cultured cells. To further investigate the pleiotropic 
effect of gene $y c h \mathrm{O}$ to all of these biological characteristics we used the transcriptome sequencing (RNAseq) analysis to compare the transcription profiles of the mutant strain and its wild-type strain. We found that 426 genes were affected upon $y c h \mathrm{O}$ deletion, which were classified into 14 broad categories (Fig. 6a) using Ecocyc and Uniprot. Most of affected genes are classified in metabolism (23.17\%), hypothetical (20.42\%) and membrane transport (17.61\%). Among the altered genes, $93.66 \%$ were downregulated in the mutant (Fig. 6b). The RNAseq was validated by comparison of the expression levels of the genes csgA, $l p f \mathrm{~A}, f i m \mathrm{H}, f l i \mathrm{C}, f l h \mathrm{D}, m o t \mathrm{~A}, f l g \mathrm{E}, e c p$ and $y c h \mathrm{O}$ by qRTPCR technique. The results were similar for both techniques (data not shown).

The high expression of $y c h \mathrm{O}$ in strain SEPT362 in lungs and spleens during infection and the possible membrane location of protein YchO suggest that the lack of this protein could generate a breakdown of the bacterial membrane, deregulating other membranelocated proteins and membrane transport proteins,

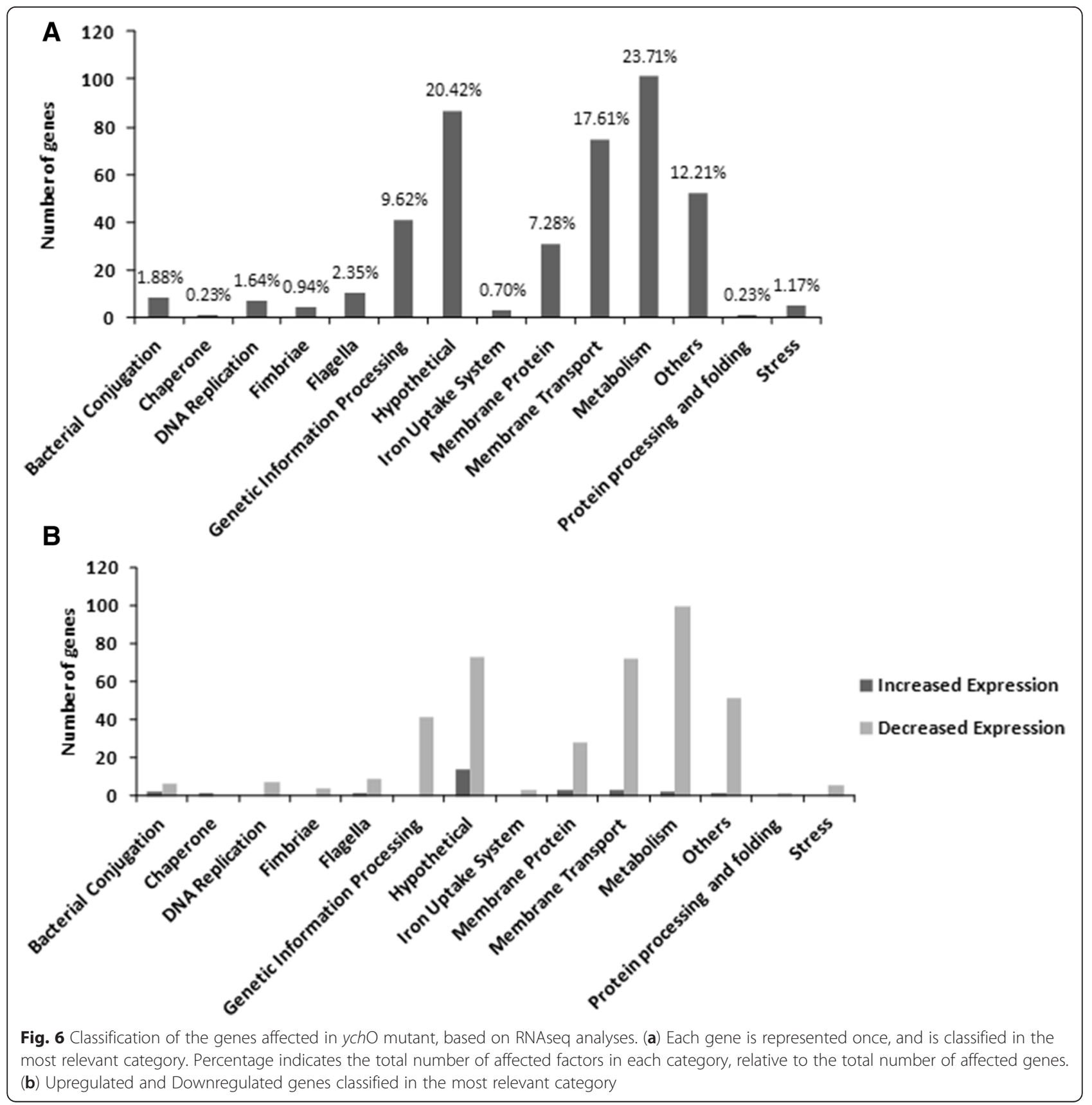


triggering a pleiotropic effect, deregulating genes related to metabolism and thus several biological characteristics.

\section{Conclusions}

The adhesion, invasion and biofilm formation results presented in this paper together with the presence of the three basic structures of the protein (peptide signal, $\beta$ Barrel and passenger domain), allow us to suggest that gene Ycho protein plays roles as an adhesin/invasion in this specific strain. Despite its short passenger protein structure, without the BID, the protein is important for the virulence of APEC strain SEPT362. With the lack of $y c h \mathrm{O}$ gene, there was a decrease in mortality in chicks. These results, together with the alteration of the expression of 426 genes, led us to propose that $y c h \mathrm{O}$ has a pleiotropic action in APEC strain SEPT362 probably due to an imbalance effect on membrane structure what leads to the altered expression of membrane-related and metabolic genes.

\section{Methods}

\section{Ethics statement}

This study was conducted according to the animal welfare guidelines of the World Organization for Animal Health [60], and approved by the "Ethics Committee on Animal Use-CEUA Unicamp" (Protocol number 2669-1) according to the Brazilian Legislation $\mathrm{N}^{\circ}$ 11794. The chickens were reared in boxes placed in warmed room, according to thermal comfort conditions required by chickens, fed with pathogen-free food and free access to water. After infection, animals were monitored every 68 hours. After the experiments, the birds that did not die from colibacillosis caused by inoculated bacteria were euthanized by cervical dislocation and then dissected with aseptic surgical techniques. The birds were sacrificed as a measure for preventing spreading of the disease. All efforts were made to minimize suffering.

\section{Bacterial strains and growth conditions}

The APEC strain SEPT362 (OR:H10) was isolated from the liver of a laying hen presenting clinical signs of septicemia, and it belongs to the bacterial collection of the Bacterial Molecular Biology Laboratory of the Institute of Biology of the State University of Campinas (LBMB) $[24,49]$. The genome of SEPT362 has been sequenced [22]. All strains and plasmids used in this study are listed in Table 1. Strains were grown aerobically in Dulbecco's Modified Eagle's Medium (DMEM - Nutricell) or Luria-Bertani medium (LB). Antibiotics were added in both media at the following concentrations: $100 \mu \mathrm{g} \mathrm{ml}^{-1}$ ampicillin (Amp), $30 \mu \mathrm{g} \mathrm{ml}^{-1}$ chloramphenicol (Cm), $25 \mu \mathrm{g} \mathrm{ml}^{-1}$ tetracycline (Tet) and $50 \mu \mathrm{g} \mathrm{ml}^{-1}$ kanamycin $(\mathrm{Km})$. Molecular biology techniques were performed as previously described [28].

\section{In silico characterization of the invasin ycho}

The NCBI Prokaryotic Genomes Automatic Annotation Pipeline (PGAAP) was employed for gene annotation (http://www.ncbi.nlm.nih.gov/genome/annotation_prok/) of APEC strain SEPT362 [22]. A survey of this genome demonstrated the existence of a gene $(y c h \mathrm{O})$ described as a putative invasin homologous to the not yet described gene $y c h \mathrm{O}$ from $E$. coli str. K-12 substr. MG1655 and present in contig24 from base 40482 to base 41735 . This gene was re-annotated by RAST (Rapid Annotation using Subsystem Technology) (http://rast.nmpdr.org/rast.cgi) [25] to confirm the gene size and composition. A topological prediction was obtained by the I-Tasser server [61].

Table 1 Strains and plasmids used in this work

\begin{tabular}{|c|c|c|}
\hline Strain or plasmid & Characteristics & Reference or source \\
\hline SEPT362 & APEC strain isolated from a septicemic laying hen & [24] \\
\hline SEPT $362 \mathrm{Cm}$ & SEPT362 with plasmid pKD46Cm & This study \\
\hline$\Delta y c h O$ & ychO mutant & This study \\
\hline C. $\Delta y c h O$ & ychO mutant complemented with plasmid pC. $\Delta y c h O$ & This study \\
\hline pACYC184 & cloning vector & New England Biolabs \\
\hline pKD4 & $\begin{array}{l}\text { pANTS derivative plasmid containing FRT-flanked } \\
\text { kanamycin resistance }\end{array}$ & [63] \\
\hline pKD3 & $\begin{array}{l}\text { pANTS derivative plasmid containing FRT-flanked } \\
\text { chloramphenicol resistance }\end{array}$ & [63] \\
\hline pKD46 & $\lambda$ Red recombinase expression plasmid & [63] \\
\hline pKD46Cm & Plasmid pKD46 with a chloramphenicol cassette insertion & This study \\
\hline $\mathrm{pC} . \Delta y c h O$ & Plasmid pACYC184 with ychO & This study \\
\hline
\end{tabular}




\section{RNA extraction}

Cultures were grown overnight in LB medium at $37{ }^{\circ} \mathrm{C}$, diluted 1:100 in DMEM and grown at $150 \mathrm{rpm}$ to an $\mathrm{OD}_{600}$ of 0.5 . RNA was extracted by using the RNAeasy Mini Kit (QIAGEN) according to the manufacturer's protocol.

\section{In vivo analysis of ycho gene expression}

The expression of the $y c h \mathrm{O}$ gene in the lungs and spleen of infected chicks was verified using qRT-PCR. For this purpose, bacterial cultures were grown overnight in LB medium at $37{ }^{\circ} \mathrm{C}$, washed and resuspended in $0.1 \mathrm{~mL}$ of sterile phosphate buffered saline (PBS) at a density of $10^{9} \mathrm{CFU} \mathrm{ml}{ }^{-1}$ and injected into the right thoracic air sac of ten one-day-old chicks (Cobb line). At 24 or $48 \mathrm{~h}$ post infection, surviving chicks were euthanized, and the lungs and spleens were removed, processed for RNA extraction using the RNAeasy Mini Kit (QIAGEN) and assayed by qRT-PCR.

\section{Quantitative real time PCR assay}

The qRT-PCR assay was performed in a one-step reaction using the ABI StepOne Plus Real-Time PCR (Applied Biosystems), in triplicate (technical replicates) using samples from three independent experiments (biological replicates). Each reaction contained $6 \mu \mathrm{l}$ of 2X SYBR Green Reaction Mix with Rox, $0.25 \mu \mathrm{l}$ of SuperScript III RT/Platinum Taq Mix (Invitrogen), 100 $\mathrm{nM}$ of each primer, $1 \mathrm{ng} \mu \mathrm{l}^{-1}$ RNA and sufficient DEPC water for a final volume of $12 \mu \mathrm{l}$. The rpoA gene was used as the endogenous control. Data collection was performed using the ABI StepOne ${ }^{\mathrm{TM}}$ Real-Time PCR software v.2.1 (Applied Biosystems). Data were normalized to levels of rpoA and analyzed using the comparative critical threshold $\left(C_{T}\right)$ method [62]. Error bars represent the standard deviations (SD) of the $C_{T}$ values.

\section{Construction of the ychO mutant and the complemented strain}

The putative invasin gene $y$ chO of strain SEPT362 $(1,254 \mathrm{bp})$ was deleted together with the sequence of its signal peptide (141 bp upstream of the $y$ chO gene). The mutant strain $\Delta y c h \mathrm{O}$ was constructed using the $\lambda$ Red system [63], with modifications. Briefly, a pair of primers, flanked by 50 nucleotide extensions homologous to the adjacent regions of the target gene, was designed to amplify the kanamycin cassette from the plasmid pKD4. One microgram of purified PCR product was electroporated into strain SEPT362 containing the $\lambda$ Red recombinase plasmid, pKD46Cm (modified by the insertion of the chloramphenicol cassette amplified from plasmid pKD3). Transformed bacterial cells were plated and grown at $37{ }^{\circ} \mathrm{C}$ on LB agar containing kanamycin. Deletion of the $y c h \mathrm{O}$ gene was confirmed by PCR (data not shown) using external primers for the gene. To complement the mutant strain, a DNA fragment covering the $y c h \mathrm{O}$ coding region plus its putative upstream promoter was amplified and cloned into the BamHI and SalI sites of plasmid pACYC184. The plasmid pC. $\Delta y$ chO was transformed into the $\Delta y c h \mathrm{O}$ strain, generating the complemented strain C. $\Delta y c h \mathrm{O}$. All oligonucleotides used in this work are listed in Table 2.

\section{Growth curves}

Cultures grown overnight in LB medium were adjusted to the same density based on $\mathrm{OD}_{600}$, diluted 1:100 and cultivated in DMEM and LB medium at $37{ }^{\circ} \mathrm{C}$ with agitation at 150 r.p.m. The $\mathrm{OD}_{600}$ was measured every $0.5 \mathrm{~h}$ until the bacteria reached the stationary phase.

\section{In vivo pathogenicity experiments}

Chick infections were performed as described by de Pace et al. [24] with minor modifications. Cultures of wild-type, mutant and complemented strains were grown overnight in $\mathrm{LB}$ medium at $37^{\circ} \mathrm{C}$, washed and resuspended in $0.1 \mathrm{~mL}$ sterilized PBS at a density of $10^{10} \mathrm{CFU} \mathrm{ml}^{-1}$ and injected into the right thoracic air sac of each one-day-old broiler chick. A group of 20 chicks was used for each bacterial culture. The Escherichia coli str. K-12 substr. DH10 $\beta$ was used as a negative control. The groups were observed for seven days post infection, and death was recorded every $24 \mathrm{~h}$.

\section{Bacterial adhesion to Chicken Embryo Fibroblast (CEF) cells}

Strains were evaluated for CEF cell adherence in the presence and absence of the D-mannose analog, methylalpha-D-mannopyranoside (Sigma cat. $\mathrm{n}^{\circ}$ M6882, Saint

Table 2 Oligonucleotides used for mutant and complement strains construction in this work

\begin{tabular}{|c|c|}
\hline Primer & Sequence \\
\hline \multicolumn{2}{|c|}{ Amplification of the $\mathrm{Cm}$ cassette } \\
\hline Forward & GAATIIITCGCTATAGTGTAGGCTGGAGCTGCTTC \\
\hline Reverse & GAATTITITCGCTATACATATGAATATCCTCCTTAG \\
\hline \multicolumn{2}{|c|}{ Mutagenesis } \\
\hline Forward & $\begin{array}{l}\text { TATTCTITAGGGCTATGGTIITCATTITTACCGGAAGTTA } \\
\text { CCGACGTTGTGTAGGCTGGAGCTGCTTC }\end{array}$ \\
\hline Reverse & $\begin{array}{l}\text { AGTCTCGCGTGGAAGCTGCGGTATGGGTGCATCAGGAGC } \\
\text { GCATITCTGACATATGAATATCCTCCTTAG }\end{array}$ \\
\hline \multicolumn{2}{|c|}{ Mutagenesis confirmation } \\
\hline Forward & TACCGGAAGTTACCGACGTT \\
\hline Reverse & ATCAGGAGCGCATTTTCTGA \\
\hline \multicolumn{2}{|c|}{ Genetic Complementation } \\
\hline Forward & GCTATAGTCGACGCGAGAAAATACGACAAAAG \\
\hline Reverse & GTAAGGATCCCACATGCTGAAGAAAATGAA \\
\hline
\end{tabular}


Louis, MO, USA), a potent FimH antagonist [64]. E. coli adherence to CEF cells was detected by the reduction of the tetrazolium dye MTT to formazan as previously described [65] and by determining the numbers of live bacteria adhering to the surface of pre-fixed cells. CEF cells were cultured in a 96-well plate in DMEM medium supplemented with $10 \%$ fetal bovine serum (FBS) until they reached confluence. The cells were subsequently inoculated with bacteria $\left(\mathrm{OD}_{600} \approx 1.0\right)$ at a multiplicity of infection (M.O.I.) of 10:1. The strains were grown with or without $1 \%$ of the mannose analog methyl-alpha-Dmannopyranoside. The E. coli HB101 was used as a negative control. The infection time was $1 \mathrm{~h}$, and the multiplication time was $3 \mathrm{~h}$ in LB broth. After the multiplication time, cells were washed six times with sterile PBS, and MTT solution $\left[2 \mathrm{mg} \mathrm{ml}^{-1}\right.$ (Sigma, cat. $\mathrm{n}^{\circ}$ M2003)] was added for another $2 \mathrm{~h}$ of incubation at $37^{\circ}$ $\mathrm{C}$ for MTT reduction to formazan. Following the reduction time, the supernatant solution was removed, $100 \mu \mathrm{l}$ of isopropyl alcohol:hydrochloric acid (24:1) was added, and the absorbance was measured at $570 \mathrm{~nm}$

\section{CEC-32 invasion assay}

The chicken embryonic fibroblast cell line CEC-32 [66] was used as a non-phagocytic cell to test APEC-host cell interactions. Fibroblasts were cultivated for 48 h in 24well culture-plates at $7.5 \times 10^{4}$ cells $\mathrm{cm}^{-2}$ in DMEM medium (Nutricell) with $10 \% \mathrm{FBS}$ at $37{ }^{\circ} \mathrm{C}$ in $5 \% \mathrm{CO}_{2}$. Cultures were washed and infected with bacteria at an MOI of $150: 1$ and incubated for $1 \mathrm{~h}$ at $37{ }^{\circ} \mathrm{C}$ in $5 \%$ $\mathrm{CO}_{2}$. E. coli $\mathrm{HB} 101$ was used as a negative control. The cells were then washed 3 times with PBS and incubated in DMEM with $10 \% \mathrm{FBS}$ and $50 \mu \mathrm{g} \mathrm{ml} \mathrm{m}^{-1}$ of gentamicin for $1 \mathrm{~h}$ at $37{ }^{\circ} \mathrm{C}$ in $5 \% \mathrm{CO}_{2}$. One set of cells was lysed and plated to count the bacteria. The other set of cultured cells was incubated for $1.5 \mathrm{~h}$ in DMEM (Nutricell) with $10 \%$ of fetal calf serum containing $5 \mu \mathrm{g} \mathrm{ml}^{-1}$ of gentamicin before the lysis step. For the lysis step, the wells were washed 3 times with PBS and incubated with $1 \mathrm{ml}$ of $1 \%$ Triton X-100 for 5 minutes. The suspensions were diluted (serial dilutions of 1:10) and plated on LB agar, and the CFU number per $\mathrm{ml}$ was determined by counting the colonies for each dilution.

\section{Biofilm formation}

Biofilm formation was analyzed using crystal violet staining as previously described by Christensen et al. [67]. Overnight cultures of SEPT362, $\Delta y c h \mathrm{O}$ and C. $\Delta y c h \mathrm{O}$ were inoculated in triplicate into DMEM at a 1:100 dilution in 24-well cell culture plates (polystyrene) to a final volume of $1 \mathrm{ml}$. The plates were incubated at $37{ }^{\circ} \mathrm{C}$ in a $5 \% \mathrm{CO}_{2}$ atmosphere for $24 \mathrm{~h}$. The wells were then washed 3 times with $1 \mathrm{x}$ PBS, $\mathrm{pH}$ 7.4. The cells were fixed with $1 \mathrm{ml}$ of $75 \%$ ethanol, washed 3 more times with $1 \mathrm{x}$ PBS and stained with $0.5 \%$ crystal violet for 5 min. After washing 4 times with $1 \mathrm{x}$ PBS, $\mathrm{pH} 7.4$, the crystal violet was solubilized by adding $1 \mathrm{ml}$ of $95 \%$ ethanol to each well for 2 minutes. The absorbance of this solution was determined in a spectrophotometer at $570 \mathrm{~nm}$.

\section{Global gene expression analyses by transcriptome sequencing (RNAseq)}

The mRNA transcriptome was isolated using the Ribominus $^{\text {mi }}$ Transcriptome Isolation Kit (Yeast and Bacteria) (Invitrogen - Life Technologies) according to the manufacturer's protocol. The transcriptome sequencing (RNAseq) was performed using the platform HISEQ2000 (ILLUMINA). Samples containing $2 \mathrm{mg}$ of mRNA were used for preparation of cDNA libraries specific sizes that were fragmented enzymatically repaired and linked to adapters discerned in the samples bioinformatics analyzes. After preparation, the libraries were deposited in one slide (flowcell) containing 8 channels (lanes) via the robotic instrument cBot (Illumina). The flowcell was then placed in HiSeq2000 where the sequencing occurred. At the end of the race, bioinformatics analyses were performed for gene expression comparison. The reads were aligned with the Open Read Frames (ORFs) and non-coding transcripts from SEPT362 strain. The alignment was performed by using the Bowtie program [68], allowing 2 mismatches. The transcript expression calculation was based on the number of aligned reads, according to Mortazavi et al. (2008) [69]. Only reads with one alignment against the ORFs were considered. Differently expressed ORFs were indentified based on the number of reads with one alignment each. Statistic analyses were performed using R De-Seq [70]. According to the program authors, ORFs less expressed in each of the analyses were excluded from the statistics tests. The

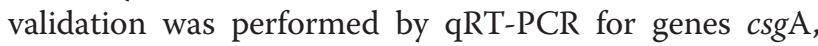
$l p f \mathrm{~A}, f i m \mathrm{H}, f l i \mathrm{C}, f l h \mathrm{D}, m o t \mathrm{~A}, f l g \mathrm{E}, e c p$ and $y c h \mathrm{O}$.

\section{Statistical analysis}

All in vitro assays were performed in triplicate. The results of adhesion, invasion, biofilm formation and qRT-PCR assays were compared using a Tukey test. Statistical analyses were performed with ASSISTAT Version 7.6 Beta (2012). RNAseq statistic analyses were performed using R De-Seq. For the chick infection assays, the Log-rank (Mantel-Cox) test was performed using GraphPad Prism version 5.00 for Windows, GraphPad Software, San Diego California USA, www.graphpad.com. Differences were considered significant at a $P$ value of $<0.05$. 


\section{Competing interests}

The authors declare that they have no competing interests.

\section{Authors' contributions}

LP participated in the design of the study, carried out the invasion, macrophage, biofilm, motility and RNAseq assays, performed the statistical analysis, and drafted the manuscript. JBP and LP carried out the construction of mutant and complemented strain and the in vivo pathogenicity experiments. TCGR carried out the in silico characterization. JLL carried out the quantitative Real-Time-PCR analysis. RAC and GN carried out the adhesion assays. WDS conceived the study, participated in its design and coordination, was responsible for all the necessary funds and helped out to draft the manuscript. All authors red and approved the final manuscript.

\section{Acknowledgements}

The authors are thankful to Globo Aves for donating the one-day-old chicks, to Prof. Dr. Fabiana Horn (Federal University of Rio Grande do Sul) for providing the avian macrophage cells and to Prof. Dr. Clarisse Weis Arns for providing the chicken embryo fibroblast cells. This work was funded by Fundação de Amparo à Pesquisa do Estado de São Paulo (2012/04391-1 and 2012/09655-7). WDS has a scientific fellowship from CNPq.

We thank the staff of the Life Sciences Core Facility (LaCTAD) from State University of Campinas (UNICAMP), for the Transcriptome and Bioinformatics analysis.

\section{Author details}

'Department of Genetics, Evolution and Bioagents, Institute of Biology (P.O.Box: 6109), State University of Campinas - UNICAMP (ZIP Code 13083970), Campinas, São Paulo, Brazil. ²Department of Microbiology, Center of Biological Sciences, State University of Londrina (UEL), Londrina, Paraná, Brazil.

Received: 17 April 2015 Accepted: 2 March 2016

Published online: 10 March 2016

\section{References}

1. Ewers C, Li G, Wilking H, Kießling S, Alt K, Antáo E-M, et al. Avian pathogenic, uropathogenic, and newborn meningitis-causing Escherichia coli: How closely related are they? Int J Med Microbiol. 2007;297:163-76.

2. Johnson JR, Russo T a. Extraintestinal pathogenic Escherichia coli: "The other bad E coli". J Lab Clin Med. 2002;139:155-62.

3. Ron EZ. Host specificity of septicemic Escherichia coli: human and avian pathogens. Curr Opin Microbiol. 2006;9:28-32

4. Dho-Moulin M, Fairbrother JM. Avian pathogenic Escherichia coli (APEC). Vet Res. 1999;30:299-316.

5. Barnes HJ, Vaillancourt JP, Gross WB. Colibacillosis. Dis Poult. 2003;11:631-52.

6. La Ragione RM, Woodward MJ. Virulence factors of Escherichia coli serotypes associated with avian colisepticaemia. Res Vet Sci. 2002;73:27-35.

7. Rodriguez-Siek KE, Giddings CW, Doetkott C, Johnson TJ, Nolan LK. Characterizing the APEC pathotype. Vet Res. 2005;36:241-56.

8. Boyer F, Fichant G, Berthod J, Vandenbrouck Y, Attree I. Dissecting the bacterial type $\mathrm{VI}$ secretion system by a genome wide in silico analysis: what can be learned from available microbial genomic resources? BMC Genomics. 2009;10:104

9. Meyer DH, Mintz KP, Fives-Taylor PM. Models of invasion of enteric and periodontal pathogens into epithelial cells: a comparative analysis. Crit Rev Oral Biol Med. 1997;8:389-409.

10. Niemann HH, Schubert W-D, Heinz DW. Adhesins and invasins of pathogenic bacteria: a structural view. Microbes Infect. 2004;6:101-12

11. Saltman LH, Lu Y, Zaharias EM, Isberg RR. A region of the Yersinia pseudotuberculosis invasin protein that contributes to high affinity binding to integrin receptors. J Biol Chem. 1996;271:23438-44.

12. Isberg RR, Leong JM. Multiple beta 1 chain integrins are receptors for invasin, a protein that promotes bacterial penetration into mammalian cells. Cell. 1990;60:861-71.

13. Jerse a E, Yu J, Tall BD, Kaper JB. A genetic locus of enteropathogenic Escherichia coli necessary for the production of attaching and effacing lesions on tissue culture cells. Proc Natl Acad Sci U S A. 1990;87:7839-43.

14. Isberg RR, Voorhis DL, Falkow S. Identification of invasin: A protein that allows enteric bacteria to penetrate cultured mammalian cells. Cell. 1987;50:769-78
15. Grassl G a, Bohn E, Müller Y, Bühler OT, Autenrieth IB. Interaction of Yersinia enterocolitica with epithelial cells: invasin beyond invasion. Int J Med Microbiol. 2003;293:41-54.

16. Hynes RO. Integrins: versatility, modulation, and signaling in cell adhesion. Cell. 1992;69:11-25.

17. Frankel G, Candy DC, Everest P, Dougan G. Characterization of the Cterminal domains of intimin-like proteins of enteropathogenic and enterohemorrhagic Escherichia coli, Citrobacter freundii, and Hafnia alvei. Infect Immun. 1994;62:1835-42.

18. Frankel G, Phillips AD, Rosenshine I, Dougan G, Kaper JB, Knutton S. Enteropathogenic and enterohaemorrhagic Escherichia coli: more subversive elements. Mol Microbiol. 1998;30:911-21.

19. Fairman JW, Dautin N, Wojtowicz D, Liu W, Noinaj N, Barnard TJ, et al. Crystal structures of the outer membrane domain of intimin and invasin from Enterohemorrhagic E. coli and Enteropathogenic Y. pseudotuberculosis. Structure. 2012;20:1233-43.

20. Touzé T, Hayward RD, Eswaran J, Leong JM, Koronakis V. Self-association of EPEC intimin mediated by the $\beta$-barrel-containing anchor domain: a role in clustering of the Tir receptor. Mol Microbiol. 2004;51:73-87.

21. Rojas TCG, Parizzi LP, Tiba MR, Chen L, Pereira GAG, Sangal V, et al. Draft genome of a brazilian avian-pathogenic Escherichia coli strain and in silico characterization of virulence-related genes. J Bacteriol. 2012;194:3023.

22. Rojas TCG, Maluta RP, Parizzi LP, Koenigkan LV, Yang J, Yu J, et al. Genome sequences of avian pathogenic Escherichia coli strains isolated from brazilian commercial poultry. Genome Announc. 2013;1.

23. Mangiamele P, Nicholson B, Wannemuehler $Y$, Seemann T, Logue CM, Li G, et al. Complete genome sequence of the avian pathogenic Escherichia coli. Genome Announc. 2013:1:2-3.

24. de Pace F, Nakazato G, Pacheco A, Boldrin de Paiva J, Sperandio V, Dias da Silveira $\mathrm{W}$. The type $\mathrm{VI}$ secretion system plays a role in type 1 fimbria expression and pathogenesis of an avian pathogenic Escherichia coli strain. Infect Immun. 2010;78:4990-8.

25. Aziz RK, Bartels D, Best AA, DeJongh M, Disz T, Edwards R a, et al. The RAST Server: rapid annotations using subsystems technology. BMC Genomics. 2008;9:75

26. Tsai JC, Yen M-R, Castillo R, Leyton DL, Henderson IR, Saier MH. The bacteria intimins and invasins: a large and novel family of secreted proteins. PLoS One. 2010:5:e14403.

27. Hamburger ZA, Brown MS, Isberg RR, Bjorkman PJ. Crystal structure of invasin: a bacterial integrin-binding protein. Science (80- ). 1999;286:291-5.

28. Sambrook J, Fritsch EF, Maniatis T: Molecular Cloning: A Laboratory Manual. 2nd edition. Volume 3. New York: Cold Spring Harbor Laboratory; 1989.

29. Antão E-M, Wieler LH, Ewers C. Adhesive threads of extraintestinal pathogenic Escherichia coli. Gut Pathog. 2009;1:22.

30. Finlay BB, Ruschkowski S, Dedhar S. Cytoskeletal rearrangements accompanying Salmonella entry into epithelial cells. J Cell Sci. 1991;99:283-96.

31. Bahrani-Mougeot FK, Buckles EL, Lockatell CV, Hebel JR, Johnson DE, Tang CM, et al. Type 1 fimbriae and extracellular polysaccharides are preeminent uropathogenic Escherichia coli virulence determinants in the murine urinary tract. Mol Microbiol. 2002;45:1079-93.

32. Boudeau J, Barnich N, Darfeuille-Michaud A. Type 1 pili-mediated adherence of Escherichia coli strain LF82 isolated from Crohn's disease is involved in bacterial invasion of intestinal epithelial cells. Mol Microbiol. 2001:39:1272-84.

33. Khan NA, Kim Y, Shin S, Kim KS. FimH-mediated Escherichia coli K1 invasion of human brain microvascular endothelial cells. Cell Microbiol. 2007;9:169-78.

34. Marc D, Arné P, Brée A, Dho-Moulin M. Colonization ability and pathogenic properties of a fim- mutant of an avian strain of Escherichia coli. Res Microbiol. 1998;149:473-85.

35. Marc D, Arne P, Brée A, Schouler C, Dho-Moulin M. Increased tracheal colonization in chickens without impairing pathogenic properties of avian pathogenic Escherichia coli MT78 with a fimH deletion. Avian Dis. 2000;44:343-55.

36. Rendón MA, Saldaña Z, Erdem AL, Monteiro-Neto V, Vázquez A, Kaper JB, et al. Commensal and pathogenic Escherichia coli use a common pilus adherence factor for epithelial cell colonization. Proc Natl Acad Sci U S A. 2007;104:10637-42.

37. Farfan MJ, Cantero L, Vidal R, Botkin DJ, Torres AG. Long polar fimbriae of enterohemorrhagic Escherichia coli 0157:H7 bind to extracellular matrix proteins. Infect Immun. 2011:79:3744-50.

38. Uhlich G a, Gunther NW, Bayles DO, Mosier D a. The CsgA and Lpp proteins of an Escherichia coli 0157:H7 strain affect HEp-2 cell invasion, motility, and biofilm formation. Infect Immun. 2009;77:1543-52. 
39. Li G, Feng Y, Kariyawasam S, Tivendale KA, Wannemuehler Y, Zhou F, et al. AatA is a novel autotransporter and virulence factor of avian pathogenic Escherichia coli. Infect Immun. 2010;78:898-906.

40. Wang S, Xia Y, Dai J, Shi Z, Kou Y, Li H, et al. Novel roles for autotransporter adhesin AatA of avian pathogenic Escherichia coli: colonization during infection and cell aggregation. FEMS Immunol Med Microbiol. 2011;63:328-38.

41. Zhuge X, Wang S, Fan H, Pan Z, Ren J, Yi L, et al. Characterization and functional analysis of AatB, a novel autotransporter adhesin and virulence factor of avian pathogenic Escherichia coli. Infect Immun. 2013;81:2437-47.

42. Li MF, Hu YH, Zheng WJ, Sun BG, Wang CL, Sun L. Inv1: an Edwardsiella tarda invasin and a protective immunogen that is required for host infection. Fish Shellfish Immunol. 2012:32:586-92.

43. Seo KS, Kim JW, Park JY, Viall AK, Minnich SSA, Rohde HN, et al. Role of a new intimin/invasin-like protein in Yersinia pestis virulence. Infect Immun. 2012:80:3559-69.

44. Duan Q, Zhou M, Liang H, Zhu X, Guo Z, Li Y, et al. Contribution of flagellin subunit FliC to piglet epithelial cells invasion by F18ab E. coli. Vet Microbiol. 2013;166:220-4.

45. Smith EJ, Thompson AP, Clarke DJ: Pathogenesis of adherent-invasive. Future Microbiol. 2013;8:1289-1300

46. Wang S, Shi Z, Xia Y, Li H, Kou Y, Bao Y, et al. IbeB is involved in the invasion and pathogenicity of avian pathogenic Escherichia coli. Vet Microbiol. 2012;159:411-9.

47. Beloin C, Roux A, Ghigo J-M. Escherichia coli Biofilms. Curr Top Microbiol Immunol. 2008;322:249-89.

48. Branda SS, Vik S, Friedman L, Kolter R. Biofilms: the matrix revisited. Trends Microbiol. 2005:13:20-6.

49. de Pace F, Boldrin de Paiva J, Nakazato G, Lancellotti M, Sircili MP, Guedes Stehling E, et al. Characterization of IcmF of the type VI secretion system in an avian pathogenic Escherichia coli (APEC) strain. Microbiology. 2011;157:2954-62.

50. Dong X, Fan X, Wang B, Shi X, Zhang XH. Invasin of Edwardsiella tarda is essential for its haemolytic activity, biofilm formation and virulence towards fish. J Appl Microbiol. 2013;115:12-9.

51. Dozois CM, Daigle F, Curtiss R. Identification of pathogen-specific and conserved genes expressed in vivo by an avian pathogenic Escherichia coli strain. Proc Natl Acad Sci U S A. 2003;100:247-52.

52. Parreira VR, Gyles CL. Shiga toxin genes in avian Escherichia coli. Vet Microbiol. 2002;87:341-52.

53. Knöbl T, Gomes TAT, Vieira MAM, Bottino JA, Ferreira AJP. Occurrence of adhesin-encoding operons in Escherichia coli isolated from breeders with salpingits and chicks with omphalitis. Brazilian J Microbiol. 2006;37:140-3.

54. McPeake SJW, Smyth J, Ball HJ. Characterisation of avian pathogenic Escherichia coli (APEC) associated with colisepticaemia compared to fecal isolates from healthy birds. Vet Microbiol. 2005;110:245-53.

55. Kostakioti M, Stathopoulos C. Functional analysis of the tsh autotransporter from an avian pathogenic Escherichia coli Strain. Infect Immun. 2004;72: 5548-54.

56. Amabile de Campos T, Stehling EG, Ferreira A, Pestana de Castro AF, Brocchi M, Dias da Silveira W. Adhesion properties, fimbrial expression and PCR detection of adhesin-related genes of avian Escherichia coli strains. Vet Microbiol. 2005;106:275-85.

57. Kariyawasam S, Johnson TJ, Nolan LK. The pap operon of avian pathogenic Escherichia coli strain 01:K1 is located on a novel pathogenicity island. Infect Immun. 2006;74:744-9.

58. Mellata M, Dho-moulin M, Dozois CM, lii RC, Brown PK, Arné P, et al. Role of virulence factors in resistance of avian pathogenic Escherichia coli to serum and in pathogenicity. Infect Immun. 2003;71:536-40.

59. Janßen T, Schwarz C, Preikschat P, Voss M, Philipp H-C, Wieler LH: Virulenceassociated isolated genes in avian pathogenic Escherichia coli (APEC) from internal organs of poultry having died from colibacillosis. Int J Med. Microbiol. 2001;378:371-378.

60. World Organization for Animal Health. Terrestrial Animal Health Code. Paris: World Organization for Animal Health; 2011.

61. Zhang Y. I-TASSER server for protein 3D structure prediction. BMC Bioinformatics. 2008:9:40

62. Walters M, Sircili MP, Sperandio V. Al-3 Synthesis Is Not Dependent on luxS in Escherichia coli. J Bacteriol. 2006;188:5668-81.

63. Datsenko KA, Wanner BL. One-step inactivation of chromosomal genes in Escherichia coli K-12 using PCR products. Proc Natl Acad Sci. 2000;97:6640-5.
64. Abgottspon D, Rölli G, Hosch L, Steinhuber A, Jiang X, Schwardt O, et al. Development of an aggregation assay to screen FimH antagonists. J Microbiol Methods. 2010;82:249-55.

65. Zaas DW, Duncan MJ, Li G, Wright JR, Abraham SN. Pseudomonas invasion of Type I pneumocytes is dependent on the expression and phosphorylation of caveolin-2. J Biol Chem. 2005;280:4864-72.

66. Kaaden OR, Lange S, Stiburek B. Establisment and characterization of chicken embryo fibroblast clone LSCC-H32. In Vitro. 1982;18:0827-34.

67. Christensen GD, Simpson WA, Younger JJ, Baddour LM, Barrett FF, Melton $\mathrm{DM}$, et al. Adherence of coagulase-negative Staphylococci to plastic tissue culture plates: a quantitative model for the adherence of Staphylococci to medical devices. J Clin Microbiol. 1985;22:996-1006.

68. Langmead B, Trapnell C, Pop M, Salzberg SL. Ultrafast and memory-efficient alignment of short DNA sequences to the human genome. Genome Biol. 2009:10:R25.

69. Mortazavi A, Williams BA, McCue K, Schaeffer L, Wold B. Mapping and quantifying mammalian transcriptomes by RNA-Seq. Nat Meth. 2008;5:621-8.

70. Anders S, Huber W. Differential expression analysis for sequence count data. Genome Biol. 2010;11:R106.

\section{Submit your next manuscript to BioMed Central and we will help you at every step:}

- We accept pre-submission inquiries

- Our selector tool helps you to find the most relevant journal

- We provide round the clock customer support

- Convenient online submission

- Thorough peer review

- Inclusion in PubMed and all major indexing services

- Maximum visibility for your research

Submit your manuscript at www.biomedcentral.com/submit
) Biomed Central 